\title{
Pay for performance with motivated employees*
}

\author{
Claudia Cerrone $^{\dagger} \quad$ Ester Manna ${ }^{\ddagger}$
}

\begin{abstract}
Heterogeneity in intrinsic motivation affects the optimal contract offered to employees in teams. Under individual incentives, the effort exerted by both motivated and selfish employees is distorted. This distortion is mitigated if employees receive a wage based on team performance. As a result, the principal prefers to use team incentives, while motivated employees are better off with individual incentives.
\end{abstract}

JEL classification: D03; D82; D86.

Keywords: Adverse selection; intrinsic motivation; individual and team incentives.

\section{Introduction}

To screen and motivate employees working in teams, firms make use of compensation schemes linked to individual and/or team performance (see Hamilton et al., 2003, Bryson et al., 2012). Which is the optimal compensation scheme in sectors where employees work in teams and tend to be intrinsically motivated towards the projects they undertake? This is a relevant question, as it is well known that, especially in the public service sector, individuals are heterogenous in their intrinsic motivation, i.e. they are interested not only in their monetary compensation but also in the project's outcome (see Shields and Ward, 2001, Antonazzo et al., 2003, Ikenwilo and Scott, 2007, and Leonard and Masatu, 2010).

This paper studies the optimal employment contract offered to intrinsically motivated employees when their motivation is their private information and they work in teams. In particular, we explore whether the employer will prefer to pay her employees based on their individual or team performance. We find that when the employer offers her employees individual incentives, the effort levels of both motivated and selfish employees are distorted downwards. However, this distortion is mitigated under team incentives, as the employer adopts a more complete contract

${ }^{*}$ We are grateful to Alastair Ball, Alessandro De Chiara, Georg Kirchsteiger. Ester Manna also acknowledges the financial support of the Ministerio de Economía y Competitividad and Fondo Europeo de Desarrollo Regional through grant ECO2015-66701-R (MINECO/FEDER, UE) and the Government of Catalonia through grant 2014SGR493. A previous version of this manuscript circulated under the title "Intrinsically motivated agents in teams".

${ }^{\dagger}$ Max Planck Institute for Research on Collective Goods, Kurt-Schumacher-Str. 10, 53113, Bonn, Germany. E-mail: cerrone@coll.mpg.de.

${ }^{\ddagger}$ Universitat de Barcelona, Department of Economic Theory, Av. Diagonal, 696, 08034 Barcelona, Spain. E-mail: estermanna@ub.edu. 
that depends on both employees' effort levels. Team incentives allow the employer to pay a lower information rent to motivated employees and, as a result, to obtain a higher profit.

We contribute to the literature on intrinsically motivated employees and adverse selection (see, among others, Delfgaauw and Dur, 2007, 2008, Barigozzi and Burani, 2016). The present article departs from the previous literature by considering teamwork and consequently the possibility that the employer offers team incentives. In this vein, our paper is closely related to Kosfeld and von Siemens (2009, 2011, 2014). They also consider team production and adverse selection, but they focus on the externalities generated by conditionally cooperative employees. By focusing on an adverse-selection problem, our paper complements the literature that studies optimal incentive contracts offered to intrinsically-motivated employees in a moral-hazard setting (see among others Itoh, 2004, and Friebel and Schnedler, 2011).

\section{$2 \quad$ Model}

We develop a model where a principal hires two employees to work on a joint project. The principal offers her employees a contract that consists of a wage, $\omega$, and effort, $e$. The effort of each employee is observable and contractible. The principal has the following profit function:

$$
\Pi=f\left(e_{A}, e_{B}\right)-\omega_{A}-\omega_{B},
$$

where $f\left(e_{A}, e_{B}\right)$ represents the principal's gross profits from the project. The function is symmetric, strictly increasing in the effort of both employees, concave and twice continuously differentiable with $f(0,0)=0, f_{e_{i}}>0, f_{e_{i} e_{j}} \geq 0$, and $f_{e_{i} e_{i}} \leq 0$ with $i, j=A, B$ and $i \neq j$. The results of the paper will hold for any concave function that is monotonically increasing in the effort levels and assigns equal weight to them. However, for illustrative purposes and to ensure that our results do not depend on the complementarity/substitutability of the production function, we focus our analysis on the following two main specifications:

1. A Cobb-Douglas function: $f\left(e_{A}, e_{B}\right)=\sqrt{e_{A} e_{B}}$.

2. A linear function: $f\left(e_{A}, e_{B}\right)=e_{A}+e_{B}$.

The key assumption of this model is that the employees can be intrinsically motivated. This means that they may care not only about their wage but also about the outcome of the project they undertake. As the outcome depends on the effort provided by both employees, the utility of a motivated employee depends also on his teammate's effort. Employee $i$ 's utility is:

$$
V_{i}\left(\omega_{i}, e_{i} ; \theta_{i}\right)=\omega_{i}-\frac{1}{2} e_{i}^{2}+\theta_{i} f\left(e_{i}, e_{j}\right)
$$

The cost of exerting effort is given by a quadratic cost function $C\left(e_{i}\right)=\frac{1}{2} e_{i}^{2}$. The exogenous parameter $\theta_{i} \geq 0$ represents employee $i$ 's intrinsic motivation with respect to the project and it is their private information. ${ }^{1}$ There are two types of employees: self-interested with $\theta_{i}=\underline{\theta}=0$

\footnotetext{
${ }^{1}$ The information asymmetry is uni-dimensional. As observed for example by Cassar (2016), mechanism design problems where the information asymmetry is multi-dimensional are hardly tractable and highly dependent on parameters' values and functions' specifications.
} 
and motivated with $\theta_{i}=\bar{\theta}>0 .^{2}$ The unconditional probability that the employee is either type is $1 / 2$; the probability that the employee is a high (low) type conditional on his teammate being a high (low) type is denoted by $\mu$. Employees are risk neutral, wealth constrained and have a reservation wage of zero.

The timing of the game is as follows. In stage 0 , each employee is informed about his motivation towards the project; in stage 1, the principal offers a menu of contracts consisting of levels of effort and wages; in stage 2, employees independently decide whether or not to accept the contract. In stage 3, the effort is exerted, production is undertaken, wages are paid, and profits are realized.

The model is solved under the assumption that the type of contract chosen by each agent becomes known before production starts (between stages 2 and 3). This assumption allows the principal to potentially condition each agent's wage and level of performance on those chosen by his teammate. ${ }^{3}$ Parties are unable to renegotiate the contract.

\section{Benchmark}

If the employees' motivation is observable, the principal can exactly compensate each employee for their production cost. The wages cover the cost of effort net of the intrinsic benefit derived from the project, making each employee indifferent between accepting and rejecting the contract, given the required level of effort:

$$
\omega_{i}=\frac{1}{2} e_{i}^{2}-\theta_{i} f\left(e_{i}, e_{j}\right)
$$

Proposition 1. Under perfect information on motivation, the principal requires the same level of effort from both employees, for any team composition.

Independently of the production function considered, the principal asks the employees to exert the same level of effort, even if the team is heterogeneous, i.e. $\theta_{A} \neq \theta_{B}$. This would not happen in an adverse selection model with heterogeneity in productivity. The intuition is the following. While in the standard model the principal would obtain a higher marginal revenue from the high type and thus would require a higher level of effort from him, in our model the principal obtains the same marginal revenue from both types. This is due to the fact that in our model the principal can extract motivated employees' intrinsic utility, which is generated by the effort levels of both motivated and selfish employees. For the same effort, motivated employees receive a lower wage than selfish employees.

\footnotetext{
${ }^{2}$ We assume that the principal and the employees obtain the same benefits from the project, namely $f\left(e_{i}, e_{j}\right)$. Therefore, an alternative interpretation of $\theta_{i}$ is that employees may have altruistic preferences towards the principal, as they internalize the principal's utility.

${ }^{3}$ As each agent is initially unaware of the other agent's type, they cannot collude in Stage 2.
} 


\section{Screening problem}

When the employees' motivation is their private information, the principal maximizes her profits subject to participation and incentive constraints. We consider incentives based on individual performance, i.e. $\omega_{i}\left(e_{i}\right)$, and team performance, i.e. $\omega_{i}\left(e_{i}, e_{j}\right){ }^{4}$

Proposition 2. Under individual incentives,

(i) the principal requires higher effort from the motivated employee;

(ii) there is a distortion at the top and at the bottom.

The principal pays an information rent to the motivated employee to induce him not to mimic the selfish employee, and - if he has a motivated colleague - to compensate him for having a colleague who might mimic a selfish type. Since the information rent depends on the outcome of the project, and so on the effort of both the motivated and the selfish employees, both types of employees exert less effort than in the first best, for either production function. In particular, under the linear production function, the effort of the motivated employee is lower than the first-best effort of a motivated employee with a motivated teammate; under the Cobb-Douglas production function, the effort of the motivated employee is lower than the first best-effort of a motivated employee, regardless of his teammate's type. It follows that under individual incentives there is a double distortion. The distortion at the top is more severe under the Cobb-Douglas production function.

As the probability that an employee is motivated conditional on his teammate being motivated, $\mu$, increases, the distortion at the top is exacerbated. The intuition is the following. As a motivated employee becomes more likely to have a motivated teammate, the gain from pretending to be selfish becomes greater. To induce information revelation, the principal must pay the motivated employees a higher information rent. Since this is costly, the principal optimally reduces the effort required from motivated employees.

Proposition 3. Under team incentives,

(i) the principal requires the same level of effort from both employees in the team;

(ii) the distortion at the top is mitigated.

Under team incentives, as in the first best, the principal requires the same effort from both employees, independently of the team composition. The distortion at the top that is obtained under individual incentives is reduced under team incentives, because the principal can offer a more complete contract that depends on both employees' effort levels. In particular, for either production function, the distortion at the top when both employees in the team are motivated disappears under team incentives. There is still a distortion in the effort of a motivated employee with a selfish teammate, but overall the distortion at the top is mitigated under team incentives.

\footnotetext{
${ }^{4}$ While there are also other forms of compensation schemes, such as benefit-sharing and tournaments, individual incentives are very common in organizations and team incentives have been increasingly used over the last decade (Bryson et al., 2012). In light of this, we focus our analysis on these two forms of compensation schemes.
} 
The selfish employee who works with a motivated employee exerts more effort under team incentives than under individual incentives.

As under individual incentives, a motivated employee receives an information rent not to mimic a selfish employee. This rent crucially depends on $\bar{\theta}$ and the effort a motivated employee would expect to exert if he pretended to be selfish. In particular, the information rent is: $\bar{\theta}\left[\mu f\left(e_{i L}^{H}, e_{j H}^{L}\right)+(1-\mu) f\left(e_{i L}^{L}, e_{j L}^{L}\right)\right] .{ }^{5} \quad$ To reduce the information rent given to motivated employees, the principal distorts downward the effort requested in teams where there is at least one selfish employee. Note also that an increase in $\mu$ negatively affects the effort exerted by employees in heterogeneous teams, while it positively affects the effort exerted by selfish employees working together.

Corollary 1. Under team incentives the principal pays a lower information rent to motivated employees than under individual incentives, thus obtaining higher profits.

By offering a contract that depends on the effort of both employees, the principal can pay a lower information rent to motivated employees under team incentives than under individual incentives, and thus obtains a higher profit. It follows that the principal prefers to use team incentives, while the motivated employees are better off with individual incentives.

Our results are obtained under the assumption that employees are risk neutral. If the employees are risk-averse towards income shocks, they will be even less willing to receive a payment based on team performance. Since each employee bears a higher risk for having the contract tied to the type of his colleague, about which he is uncertain, he has to be compensated with a higher wage. As a result, profits are reduced and the principal might also be better off by using individual incentives.

\section{Conclusion}

This paper shows that, when an employer cannot observe her employees' motivation towards the project and the employees work in teams, she will prefer to pay them on the base of their team performance rather than on their individual performance. This finding complements previous findings in favour of the use of team incentives in organizations (among others, Che and Yoo, 2001, Auriol et al., 2002, Corts, 2007).

\footnotetext{
${ }^{5}$ Under team incentives, the principal can condition the agent's effort level on that of his colleague in the team. Therefore, $e_{i r}^{s}$ is the effort required by agent $i$ when his type is $r$, while the type of his colleague is $s$, where $r, s=L, H$ and $i \neq j$.
} 


\section{References}

Antonazzo, E., Scott, A., Skatun, D., Elliott, R., et al., 2003. The labour market for nursing: a review of the labour supply literature. Health Economics 12 (6), 465-478.

Auriol, E., Friebel, G., Pechlivanos, L., 2002. Career concerns in teams. Journal of Labor Economics 20 (2), 289-307.

Barigozzi, F., Burani, N., 2016. Screening workers for ability and motivation. Oxford Economic Papers 68 (2), 627-650.

Bryson, A., Freeman, R., Lucifora, C., Pellizzari, M., Perotin, V., 2012. Paying for performance: Incentive pay schemes and employees' financial participation. Tech. rep., Centre for Economic Performance, LSE.

Cassar, L., 2016. Optimal contracting with endogenous project mission. Mimeo.

Che, Y.-K., Yoo, S.-W., 2001. Optimal incentives for teams. American Economic Review, 525541.

Corts, K. S., 2007. Teams versus individual accountability: Solving multitask problems through job design. The Rand Journal of Economics 38 (2), 467-479.

Delfgaauw, J., Dur, R., 2007. Signaling and screening of workers' motivation. Journal of Economic Behavior \& Organization 62 (4), 605-624.

Delfgaauw, J., Dur, R., 2008. Incentives and workers' motivation in the public sector. The Economic Journal 118 (525), 171-191.

Friebel, G., Schnedler, W., 2011. Team governance: Empowerment or hierarchical control. Journal of Economic Behavior \& Organization 78 (1), 1-13.

Hamilton, B. H., Nickerson, J. A., Owan, H., 2003. Team incentives and worker heterogeneity: An empirical analysis of the impact of teams on productivity and participation. Journal of Political Economy 111 (3), 465-497.

Ikenwilo, D., Scott, A., 2007. The effects of pay and job satisfaction on the labour supply of hospital consultants. Health Economics 16 (12), 1303-1318.

Itoh, H., 2004. Moral hazard and other-regarding preferences. The Japanese Economic Review 55 (1), 18-45.

Kosfeld, M., von Siemens, F. A., 2009. Worker self-selection and the profits from cooperation. Journal of the European Economic Association 7 (2-3), 573-582.

Kosfeld, M., von Siemens, F. A., 2011. Competition, cooperation, and corporate culture. The RAND Journal of Economics 42 (1), 23-43. 
Kosfeld, M., von Siemens, F. A., 2014. Team production in competitive labor markets with adverse selection. European Economic Review 68, 181-198.

Leonard, K. L., Masatu, M. C., 2010. Professionalism and the know-do gap: Exploring intrinsic motivation among health workers in Tanzania. Health Economics 19 (12), 1461-1477.

Shields, M. A., Ward, M., 2001. Improving nurse retention in the National Health Service in England: the impact of job satisfaction on intentions to quit. Journal of Health Economics $20(5), 677-701$. 


\section{A Appendix}

\section{A.1 Benchmark}

Proof of Proposition 1. The principal maximizes her profits subject to equation (3). Profits can be rewritten as:

$$
\Pi=f\left(e_{A}, e_{B}\right)-\left(\frac{1}{2} e_{A}^{2}-\theta_{A} f\left(e_{A}, e_{B}\right)\right)-\left(\frac{1}{2} e_{B}^{2}-\theta_{B} f\left(e_{A}, e_{B}\right)\right) .
$$

Taking the first order condition with respect to $e_{A}$ and $e_{B}$ yields the following:

$$
\frac{\partial f\left(e_{A}, e_{B}\right)}{\partial e_{A}}\left(1+\theta_{A}+\theta_{B}\right)=e_{A} ; \quad \frac{\partial f\left(e_{A}, e_{B}\right)}{\partial e_{B}}\left(1+\theta_{A}+\theta_{B}\right)=e_{B} .
$$

Under complete information, the first-best effort levels satisfy the following conditions.

(i) If both employees are motivated, i.e. $\theta_{A}=\theta_{B}=\bar{\theta}, \quad e_{H}=\frac{\partial f\left(e_{H}, e_{H}\right)}{\partial e_{H}}(1+2 \bar{\theta})$;

(ii) If both employees are selfish, i.e. $\theta_{A}=\theta_{B}=\underline{\theta}, \quad e_{L}=\frac{\partial f\left(e_{L}, e_{L}\right)}{\partial e_{L}}$;

(iii) If only one employee is motivated, i.e. $\theta_{i}=\bar{\theta}$ and $\theta_{j}=\underline{\theta}, e_{H}=\frac{\partial f\left(e_{H}, e_{L}\right)}{\partial e_{H}}(1+\bar{\theta})$ and $e_{L}=\frac{\partial f\left(e_{L}, e_{H}\right)}{\partial e_{L}}(1+\bar{\theta})$.

Irrespective of the function we consider, the principal requires the same level of effort from both agents, even when the team is heterogeneous.

(i) If both employees are motivated,

$$
e_{H}= \begin{cases}\frac{1+2 \bar{\theta}}{2} & \text { if } f\left(e_{A}, e_{B}\right)=\sqrt{e_{A} e_{B}} \\ 1+2 \bar{\theta} & \text { if } f\left(e_{A}, e_{B}\right)=e_{A}+e_{B}\end{cases}
$$

(ii) If both employees are selfish,

$$
e_{L}= \begin{cases}\frac{1}{2} & \text { if } f\left(e_{A}, e_{B}\right)=\sqrt{e_{A} e_{B}} \\ 1 & \text { if } f\left(e_{A}, e_{B}\right)=e_{A}+e_{B}\end{cases}
$$

(iii) If only one employee is motivated,

$$
e_{H}=e_{L}= \begin{cases}\frac{1+\bar{\theta}}{2} & \text { if } f\left(e_{A}, e_{B}\right)=\sqrt{e_{A} e_{B}} \\ 1+\bar{\theta} & \text { if } f\left(e_{A}, e_{B}\right)=e_{A}+e_{B}\end{cases}
$$




\section{A.2 Screening problem}

The participation and incentive constraints are:

$$
\begin{gathered}
\omega_{i L}-\frac{1}{2} e_{i L}^{2} \geq 0 \\
\omega_{i H}-\frac{1}{2} e_{i H}^{2}+\bar{\theta}\left[\mu f\left(e_{i H}, e_{j H}\right)+(1-\mu) f\left(e_{i H}, e_{j L}\right)\right] \geq 0 \\
\omega_{i L}-\frac{1}{2} e_{i L}^{2} \geq \omega_{i H}-\frac{1}{2} e_{i H}^{2} \\
\omega_{i H}-\frac{1}{2} e_{i H}^{2}+\bar{\theta}\left[\mu f\left(e_{i H}, e_{j H}\right)+(1-\mu) f\left(e_{i H}, e_{j L}\right)\right] \geq \\
\omega_{i L}-\frac{1}{2} e_{i L}^{2}+\bar{\theta}\left[\mu f\left(e_{i L}, e_{j H}\right)+(1-\mu) f\left(e_{i L}, e_{j L}\right)\right]
\end{gathered}
$$

with $i, j \in\{A, B\}$ and $i \neq j$.

First, if equations $\left(I C_{H}\right)$ and $\left(P C_{L}\right)$ are satisfied, then

$$
\begin{gathered}
\omega_{i H}-\frac{1}{2} e_{i H}^{2}+\bar{\theta}\left[\mu f\left(e_{i H}, e_{j H}\right)+(1-\mu) f\left(e_{i H}, e_{j L}\right)\right] \geq \\
\bar{\theta}\left[\mu f\left(e_{i L}, e_{j H}\right)+(1-\mu) f\left(e_{i L}, e_{j L}\right)\right] \geq 0 .
\end{gathered}
$$

Equation (4) reflects the fact that a motivated employee receives a higher surplus from the project than a selfish one. $\left(P C_{i H}\right)$ is satisfied and cannot be binding because

$$
\bar{\theta}\left[\mu f\left(e_{i L}, e_{j H}\right)+(1-\mu) f\left(e_{i L}, e_{j L}\right)\right] \geq 0
$$

must be satisfied as well. In contrast, $\left(P C_{i L}\right)$ must be binding. Next, $\left(I C_{i H}\right)$ must be binding, otherwise the principal could increase $\omega_{i H}$ slightly and keep all the constraints satisfied. Finally, the incentive constraint for the selfish type cannot be binding given that

$$
\bar{\theta}\left[\mu f\left(e_{i H}, e_{j H}\right)+(1-\mu) f\left(e_{i H}, e_{j L}\right)\right] \geq 0
$$

must be satisfied.

Proof of Proposition 2. The participation constraint for the self-interested employees $\left(P C_{L}\right)$ and the incentive constraint for the motivated employees $\left(I C_{H}\right)$ are binding. Using $\left(P C_{L}\right)$ and $\left(I C_{H}\right)$, the optimal wages satisfy the following equation:

$$
\begin{aligned}
\omega_{i L} & =\frac{1}{2} e_{i L}^{2} ; \\
\omega_{i H} & =\frac{1}{2} e_{i H}^{2}-\bar{\theta}\left[\mu f\left(e_{i H}, e_{j H}\right)+(1-\mu) f\left(e_{i H}, e_{j L}\right)\right]+\bar{\theta}\left[\mu f\left(e_{i L}, e_{j H}\right)+(1-\mu) f\left(e_{i L}, e_{j L}\right)\right],
\end{aligned}
$$

where $\bar{\theta}\left[\mu f\left(e_{i L}, e_{j H}\right)+(1-\mu) f\left(e_{i L}, e_{j L}\right)\right]$ is the information rent paid to motivated employees. The principal maximizes profits subject to (5). Profits can be rewritten as follows:

$$
\begin{aligned}
\Pi= & \frac{\mu}{2}\left[f\left(e_{i H}, e_{j H}\right)+f\left(e_{i L}, e_{j L}\right)\right]+\frac{1-\mu}{2}\left[f\left(e_{i H}, e_{j L}\right)+f\left(e_{i L}, e_{j H}\right)\right]-\frac{1}{2}\left[\frac{1}{2} e_{i H}^{2}+\frac{1}{2} e_{j H}^{2}+\frac{1}{2} e_{i L}^{2}+\frac{1}{2} e_{j L}^{2}\right]+ \\
& +\frac{\bar{\theta}}{2}\left[2 \mu f\left(e_{i H}, e_{j H}\right)+(1-2 \mu)\left[f\left(e_{i H}, e_{j L}\right)+f\left(e_{i L}, e_{j H}\right)\right]-2(1-\mu) f\left(e_{i L}, e_{j L}\right)\right] .
\end{aligned}
$$


Taking the first order conditions with respect to $e_{i L}$ and $e_{i H}$ yields the following:

$$
\begin{aligned}
& e_{i L}=\mu\left(\frac{\partial f\left(e_{i L}, e_{j L}\right)}{\partial e_{i L}}\right)+(1-\mu)\left(\frac{\partial f\left(e_{i L}, e_{j H}\right)}{\partial e_{i L}}\right)(1+\bar{\theta})-\mu \bar{\theta}\left(\frac{\partial f\left(e_{i L}, e_{j H}\right)}{\partial e_{i L}}\right)-2(1-\mu) \bar{\theta}\left(\frac{\partial f\left(e_{i L}, e_{j L}\right)}{\partial e_{i L}}\right) ; \\
& e_{i H}=\mu\left(\frac{\partial f\left(e_{i H}, e_{j H}\right)}{\partial e_{i H}}\right)(1+2 \bar{\theta})+(1-\mu)\left(\frac{\partial f\left(e_{i H}, e_{j L}\right)}{\partial e_{i H}}\right)(1+\bar{\theta})-\bar{\theta} \mu\left(\frac{\partial f\left(e_{i H}, e_{j L}\right)}{\partial e_{i H}}\right) .
\end{aligned}
$$

Analogous expressions could be derived for agent $j$. By comparing the first-order conditions with those obtained under the first best, it can be noted that if teams consist of homogeneous agents with certainty, i.e. $\mu=1$, both motivated and selfish employees exert a lower effort than in the first best. In contrast, if teams consist of heterogeneous agents with certainty, i.e. $\mu=0$, the effort is distorted only at the bottom, as in the standard adverse selection model. Therefore, an increase in $\mu$ has a negative impact on the effort of motivated employees under individual incentives: it magnifies the distortion at the top.

For the Cobb-Douglas and linear production functions:

(i) If the employee is selfish,

$$
e_{L} \begin{cases}\in\left(\frac{1}{2}(1-\theta), \frac{1}{2}\right) & \text { if } f\left(e_{A}, e_{B}\right)=\sqrt{e_{A} e_{B}} \\ =1-\bar{\theta} & \text { if } f\left(e_{A}, e_{B}\right)=e_{A}+e_{B}\end{cases}
$$

(ii) If the employee is motivated,

$$
e_{H} \begin{cases}\in\left(\frac{1}{2}, \frac{1}{2}(1+\theta)\right) & \text { if } f\left(e_{A}, e_{B}\right)=\sqrt{e_{A} e_{B}} \\ =1+\bar{\theta} & \text { if } f\left(e_{A}, e_{B}\right)=e_{A}+e_{B}\end{cases}
$$

When $f\left(e_{A}, e_{B}\right)=e_{A}+e_{B}$, the effort of the selfish employee is lower than the first-best effort level of a selfish employee, whether his teammate is selfish or motivated. In contrast, the effort of the motivated employee equals the first-best effort of a motivated employee with a selfish teammate, but is lower than the first-best effort of a motivated employee with a motivated teammate. The latter implies that, besides the distortion at the bottom, there is also a distortion at the top. When $f\left(e_{A}, e_{B}\right)=\sqrt{e_{A} e_{B}}$, the effort of the selfish (motivated) employee is lower than the firstbest effort level of a selfish (motivated) employee, irrespective of his teammate's type. Thus, there is a distortion at the bottom and at the top.

Proof of Proposition 3. Also under team incentives $\left(P C_{L}\right)$ and $\left(I C_{H}\right)$ must be binding. ${ }^{6}$ The incentive constraint for a motivated employee requires that the expected utility that he receives is higher than the expected utility that he obtains by pretending to be selfish. In expectation, a motivated employee knows that with probability $\mu$ he will be in a team with another motivated teammate and with probability $(1-\mu)$ in a team with a selfish one. Participation constraints guarantee that in expectation both types accept the contract.

\footnotetext{
${ }^{6}$ The proof is very similar to the one provided under individual incentives and available under request.
} 
From $\left(P C_{L}\right)$ the optimal wage for selfish employees satisfies the following equation:

$$
\mu\left[\omega_{i L}\left(e_{i L}^{L}, e_{j L}^{L}\right)\right]+(1-\mu)\left[\omega_{i L}\left(e_{i L}^{H}, e_{j H}^{L}\right)\right]=\mu\left[\frac{1}{2}\left(e_{i L}^{L}\right)^{2}\right]+(1-\mu)\left[\frac{1}{2}\left(e_{i L}^{H}\right)^{2}\right] ;
$$

and from $\left(I C_{H}\right)$ the optimal wage for motivated employees satisfies the following equation:

$$
\begin{aligned}
& \mu\left[\omega_{i H}\left(e_{i H}^{H}, e_{j H}^{H}\right)\right]+(1-\mu)\left[\omega_{i H}\left(e_{i H}^{L}, e_{j L}^{H}\right)\right]=\mu\left[\frac{1}{2}\left(e_{i H}^{H}\right)^{2}-\bar{\theta} f\left(e_{i H}^{H}, e_{j H}^{H}\right)\right]+ \\
& +(1-\mu)\left[\frac{1}{2}\left(e_{i H}^{L}\right)^{2}-\bar{\theta} f\left(e_{i H}^{L}, e_{j L}^{H}\right)\right]+\bar{\theta}\left[\mu f\left(e_{i L}^{H}, e_{j H}^{L}\right)+(1-\mu) f\left(e_{i L}^{L}, e_{j L}^{L}\right)\right],
\end{aligned}
$$

where $\bar{\theta}\left[\mu f\left(e_{i L}^{H}, e_{j H}^{L}\right)+(1-\mu) f\left(e_{i L}^{L}, e_{j L}^{L}\right)\right]$ is the information rent paid to motivated employees. The principal chooses effort levels to maximize her profit function subject to (7) and (8). After some simple computations, profits can be rewritten as follows:

$$
\begin{aligned}
\Pi & =\frac{\mu}{2}\left[f\left(e_{i H}^{H}, e_{j H}^{H}\right)-\frac{1}{2}\left(e_{i H}^{H}\right)^{2}+\bar{\theta} f\left(e_{i H}^{H}, e_{j H}^{H}\right)-\frac{1}{2}\left(e_{j H}^{H}\right)^{2}+\bar{\theta} f\left(e_{i H}^{H}, e_{j H}^{H}\right)\right]+ \\
& +\frac{\mu}{2}\left[f\left(e_{i L}^{L}, e_{j L}^{L}\right)-\frac{1}{2}\left(e_{i L}^{L}\right)^{2}-\frac{1}{2}\left(e_{j L}^{L}\right)^{2}\right]+ \\
& +\frac{1-\mu}{2}\left[f\left(e_{i H}^{L}, e_{j L}^{H}\right)-\frac{1}{2}\left(e_{i H}^{L}\right)^{2}+\bar{\theta} f\left(e_{i H}^{L}, e_{j L}^{H}\right)-\frac{1}{2}\left(e_{j L}^{H}\right)^{2}\right]+ \\
& +\frac{1-\mu}{2}\left[f\left(e_{i L}^{H}, e_{j H}^{L}\right)-\frac{1}{2}\left(e_{i L}^{H}\right)^{2}-\frac{1}{2}\left(e_{j H}^{L}\right)^{2}+\bar{\theta} f\left(e_{i L}^{H}, e_{j H}^{L}\right)\right]+ \\
& -\frac{\bar{\theta}}{2}\left[\mu\left[f\left(e_{i L}^{H}, e_{j H}^{L}\right)+f\left(e_{i H}^{L}, e_{j L}^{H}\right)\right]+2(1-\mu) f\left(e_{i L}^{L}, e_{j L}^{L}\right)\right]
\end{aligned}
$$

Taking the first order conditions, the effort level must satisfy the following:

(i) If both employees are motivated, $e_{i H}^{H}=\frac{\partial f\left(e_{i H}^{H}, e_{j H}^{H}\right)}{\partial e_{i H}^{H}}(1+2 \bar{\theta})$;

(ii) If both employees are selfish, $e_{i L}^{L}=\frac{\partial f\left(e_{i L}^{L}, e_{j L}^{L}\right)}{\partial e_{i L}^{L}}\left[1-2 \bar{\theta}\left(\frac{1-\mu}{\mu}\right)\right]$;

(iii) In heterogenous teams, $e_{i H}^{L}=\frac{\partial f\left(e_{i H}^{L}, e_{j L}^{H}\right)}{\partial e_{i H}^{L}}\left[1+\bar{\theta}\left(\frac{1-2 \mu}{1-\mu}\right)\right]$ and $e_{i L}^{H}=\frac{\partial f\left(e_{i L}^{H}, e_{j H}^{L}\right)}{\partial e_{i L}^{H}}\left[1+\bar{\theta}\left(\frac{1-2 \mu}{1-\mu}\right)\right]$.

Analogous expressions could be derived for agent $j$. By symmetry, in what follows we can rewrite each effort level as $e_{i H}^{H}=e_{H}^{H}, e_{i L}^{L}=e_{L}^{L}, e_{i L}^{H}=e_{L}^{H}$ and $e_{i H}^{L}=e_{H}^{L}$. For the Cobb-Douglas and linear production functions:

(i) If both employees are motivated,

$$
e_{H}^{L}= \begin{cases}\frac{1+2 \bar{\theta}}{2} & \text { if } f\left(e_{A}, e_{B}\right)=\sqrt{e_{A} e_{B}} \\ 1+2 \bar{\theta} & \text { if } f\left(e_{A}, e_{B}\right)=e_{A}+e_{B}\end{cases}
$$

(ii) If both employees are selfish,

$$
e_{L}^{L}= \begin{cases}\frac{1}{2}\left[1-2 \bar{\theta}\left(\frac{1-\mu}{\mu}\right)\right] & \text { if } f\left(e_{A}, e_{B}\right)=\sqrt{e_{A} e_{B}} \\ 1-2 \bar{\theta}\left(\frac{1-\mu}{\mu}\right) & \text { if } f\left(e_{A}, e_{B}\right)=e_{A}+e_{B} .\end{cases}
$$


(iii) In heterogenous teams,

$$
e_{H}^{L}=e_{L}^{H}= \begin{cases}\frac{1}{2}\left[1+\bar{\theta}\left(\frac{1-2 \mu}{1-\mu}\right)\right] & \text { if } f\left(e_{A}, e_{B}\right)=\sqrt{e_{A} e_{B}} \\ 1+\bar{\theta}\left(\frac{1-2 \mu}{1-\mu}\right) & \text { if } f\left(e_{A}, e_{B}\right)=e_{A}+e_{B}\end{cases}
$$

Similarly to the first best, the principal requires the same level of effort from both agents, even when the team is heterogeneous. For either production function, under team incentives the distortion at the top when both employees are motivated disappears. However, there is a distortion for the motivated employee with a selfish teammate. This distortion allows the principal to pay a lower information rent to motivated employees, as stated by Corollary 1 . Overall, the distortion at the top is mitigated under team incentives.

It is worth noting that an increase in $\mu$ has a negative impact on the effort exerted by employees in heterogeneous teams, but positively affects the effort exerted by selfish employees working together:

$$
\frac{\partial e_{i H}^{L}}{\partial \mu}=\frac{\partial e_{i L}^{H}}{\partial \mu}=-\frac{\bar{\theta}}{(1-\mu)^{2}} \leq 0 ; \quad \frac{\partial e_{i L}^{L}}{\partial \mu}=\frac{2 \bar{\theta}}{\mu^{2}} \geq 0 .
$$

To guarantee that effort levels are not negative, it is assumed that $\mu$ belongs to the following interval: $\mu \in\left[\frac{2 \bar{\theta}}{1+2 \bar{\theta}}, \frac{1+\bar{\theta}}{1+2 \bar{\theta}}\right]$.

Proof of Corollary 1. Suppose that $f\left(e_{A}, e_{B}\right)=e_{A}+e_{B}$. The information rent paid to the motivated employee under individual incentives is given by

$$
I R^{I I}=2 \bar{\theta}[1-\bar{\theta}(1-\mu)]
$$

The information rent paid to the motivated employee under team incentives is given by

$$
I R^{T I}=2 \bar{\theta}\left[1-\frac{\bar{\theta}\left(2-6 \mu+5 \mu^{2}\right)}{\mu(1-\mu)}\right] .
$$

We find that the information rent paid to the motivated employee is always lower under team incentives than under individual incentives for any $\bar{\theta}$ and any $\mu \in(0,1)$.

Substituting the respective effort levels into equations (6) and (9), we obtain the principal's profits under individual and team incentives:

$$
\begin{gathered}
\Pi^{I I}=1+\bar{\theta}^{2} \\
\Pi^{T I}=1+\bar{\theta}^{2}\left(\frac{2}{\mu}+\frac{1}{1-\mu}-4\right) .
\end{gathered}
$$

Comparing the profits, we find that $\Pi^{T I}>\Pi^{I I}$ if $\frac{\bar{\theta}^{2}\left[2-6 \mu+5 \mu^{2}\right]}{(1-\mu) \mu}>0$, that is always the case for any $\bar{\theta}$ and any $\mu \in(0,1)$.

This result holds also when $f\left(e_{A}, e_{B}\right)=\sqrt{e_{A} e_{B}}$. The proof is similar and available upon request. 